\title{
THEORETICAL AND METHODOLOGICAL ASPECTS ON MILITARY STUDENTS' EDUCATION
}

\author{
Robert STĂNCIULESCU, Stelian POPESCU \\ “Nicolae Bălcescu” Land Forces Academy, Sibiu, Romania \\ rstanciulescu@armyacademy.ro
}

\begin{abstract}
The complexity of military actions on the modern battlefield, as well as the increase in high-tech weaponry call for a professional instruction system that requires an optimal organization, in order to be effective. The efforts to achieve this purpose are mainly targeting the didactic strategies. The paper presents a brief exposition of the forms and methods of instruction used in preparing military students, with focus on the major impacting methods used along this complex process.
\end{abstract}

\section{Keywords: military, organization, education, process, instruction}

\section{Introduction}

Modernizing instruction in the military organization includes both the educational system and the educational process. Only by putting them together into a unitary whole, will we be able to encompass the real meaning of modernization. This is due to the fact that the system offers the institutional framework for the educational process and the latter, in turn, provides the necessary means for meeting the educational objectives. It can be stated that any modification or intervention into the system will have an impact on its outcome, namely on the quality of military students' instruction.

An approximate delimitation of the modernizing process is only possible to the extent to which it is based on this interdependence between the system and process. Put together as "instruction", they are to be compared against the social context, with its increasing norms and requirements derived from the necessity of a training process compatible with that of the Euro Atlantic armies we aim to integrate in. Modernizing the methodology of instruction stays in- between social command (specialist model) and the necessity of providing efficient instruction. Modernization is a logical process consisting of a series of actions aimed at achieving consistency of the instruction process with the requirements of life in general and with the fundamental changes that have occurred in society, economy, science and technology, culture, and in the military organization, in particular.

\section{The training methods}

The modern training process based on effective training methods offers access to a quick, lasting instruction, developing in accordance with the modern requirements of the battlefield. In recent years, there have been relevant achievements pertaining to possible taxonomies and boundaries of training methodology, to reconsiderations of military, pedagogical concepts and to concordance between methodology, principles and educational methods. There 
are several classification criteria: the historical criterion with traditional or modern (interactive) methods, the scope criterion with general and particular methods, the didactic load criterion with teaching-learning methods, methods of information dissemination, organization methods and evaluation methods, the instruction process criterion and the learner-type criterion. The discrepancies among these classifications point out the dynamic aspect of the instruction methodology as well as the progress of instruction techniques.

The modernization of instruction methodology from its primary forms to the present day methods (modern methodologies of different subjects) is a process which has been contributing to the increase of efficiency within the educational process. For example the classic methods (the presentation, the conversation, the exercise, etc.) that have been solely used by instructors for a long time, are still used today together with other methods agreed by educational practice. "The choice of educational methods depends on the operational objectives of the class, on the content to be taught, on the students' level, on the material resources and the time span available".

\subsection{Methods of information dissemination}

The exposition is the oral presentation of information by the instructor, in a logical sequence. The main requirements it has to meet are the following:

a) to present exact information based on scientific facts. This information should be chosen according to the topic of the lesson; it should be explanatory and must lead to the clear understanding of the subject matter. It should persuade the student of the righteousness and authenticity of the content.

b) it must always rely on and connect to previous knowledge c) it must be logically sequenced, from concrete facts to generalizations or conversely, underpinning the main ideas of each issue

d) it must appeal to the student not only through the value of its content and delivery but also through its practical connections and examples.

e) it must be clear, with simple phrases easy to comprehend, expressed in a correct literary form as attractively as possible avoiding irrelevant details or empty phrases

f) It must be plastic in content, ideas and facts, in style, delivery and wording

The Lecture is different from the exposition in that it does not involve questions. It is used:

- in teaching introductory, theoretical classes with a more general content;

- for the detailed analysis by the instructor of an important, fairly ample issue;

- for revising and summarizing a study chapter (summary lectures).

At the end of the lecture, questions may be asked about issues that were not fully understood. The lecture must meet the same requirements as the exposition.

The Explanation is a short, clear exposition consisting either in a rational argumentation, or in the discovery and statement of the logical principles underpinning facts or phenomena. In this case, it is presented as a series of conclusions, drawn after a reasoning process, which underline and clarify the connections between phenomena or facts.

The explanation can also consist in a concise issue discussed in more extended terms, by comparing it against concrete cases.

Sometimes, the explanation accompanies the demonstration of a movement (action, physical exercise) or that of an object or of a physical or chemical process. A special form of explanation is the demonstration through calculus of a mathematical rule, a 
physical phenomenon or, more frequently, of primary data such as the width of an action area, strengthening norms or work possibilities. In addition, a conclusion drawn from a tactical situation analysis of the time necessary for finishing an engineering task for P.O, can be demonstrated through calculus.

The Description is a logically sequenced presentation of the results of observation, of a phenomenon (process, action, movement), of an object or of its representations (images), and of previously perceived facts and objects.

It is used especially in the teaching sessions, for getting to know the material (weaponry, battle techniques) but also in other forms of the instruction process such as practical classes and in the evaluation process. The explanation and the description are often combined with the exposition and the lecture. The methods of continuous and sequenced exposition are used in all the forms of the educational process. They are the main teaching and sometimes tutoring methods and they apply less to the other forms of the educational process. During the practical sessions the use of these methods has to be reduced as much as possible (short exposition of the tactical situation, of work organization, short explanations etc.).

\subsection{The Conversation (discussion, the interrogative model of inquiry)}

The Conversation is the teaching method in which the instructor addresses the military students sequenced questions in order to stimulate their thinking, to help them acquire new knowledge, deepen, organize or revise previously taught information. [1]

The conversation is used in almost all the forms of the educational process for the following purposes:

a) Linking previous and new information

b) Teaching new information, in this case, the conversation needs to build on data or facts form the military students' experience, on previous knowledge similar to the one being taught (for example, when one compares a certain type of weapons, a vehicle or an engine to the type which is being taught) and also to be based on the previous study of class bibliography.

Using the conversation as a teaching method calls for thorough preparation and strong methodological skills on the part of the instructor so that the dialog between the instructor and the military students lead directly to the "discovery" of new information and to the right conclusions. Using this conversation method, the instructor will guide the military students' thinking through questions that will use and combine their previous knowledge leading the discussion in such a way that the students would come to clear and informed conclusions about the topic of the teaching session.

The questions addressed by the instructor must not suggest students'; answers but only shape the issue under discussion. The conversation can be applied easier if it is based on realia (by observing the real phenomenon) such as an electronic device or a weapon type, etc.

c) Acquiring and deepening the new knowledge with the help of conversation occur by students' answering the instructor's questions, by revising the main ideas and the summary of what has been taught.

d) Revising the information- in this case the conversation is based on a series of logically sequenced questions addressed by the instructor, which target the revision of more previously taught units, in a unitary way.

As the partial evaluation revision cannot include all the information taught during more sessions, the conversation is limited to the fundamental problems presented in the previous sessions, which must be approached in a logical sequence.

The main requirements of the questions asked by the instructor in order to ensure efficiency of the conversation are: 
a) To be precise from the point of view of the content, to be short and accurately asked, so that they justly direct the thinking of the military.

b) To stimulate the thinking of the military students, to elicit the use of information in new combinations, to reveal various aspects of the issues, new connections besides the ones pointed out during teaching, to make the military students analyze critically and draw new conclusions, to ask them to support their opinions with arguments.

c) To be addressed, regularly, to the entire subunit, to give some time for the answer to be analyzed and organized.

\subsection{The Demonstration}

The Demonstration (demonstrative or intuitive method, the "do like me" method) consists in: [2]

- presentation of real objects (phenomena, processes) or their images (shapes) reproduced from the real object in two and three dimensions (movies, photos, models, miniatures, etc.);

- performance by the instructor or the subunit (team work) of how to execute a movement, action, work.

The main requirements of effective demonstration are:

a) the object or phenomenon to be perceived by as many senses (analyzers) as possible.

b) the observation of the military to be guided by the instructor through statements or questions in order for them to notice the characteristic, essential features of the works (materials), the main phases of the process (action, movement).

c) whenever possible and appropriate, the phenomena (processes, actions, movements) to be demonstrated in various stages of development or transformation.

This requirement must always be met in demonstrating the functionality of equipment, weapons, engines, etc., the movements during battery (platoon) field training, the physical exercises, various interior and exterior ballistic phenomena etc.

d) The movement (action, process) should be repeated as many times as it is necessary to be understood.

The demonstration takes different forms due to the great diversity of the demonstrative (intuitive) material:

- Demonstration of real (natural) objects and phenomena (processes, actions, movements, physical exercises).

- Demonstration using films (feature films or videos)

-Demonstration using photos, overhead projector and graphic materials (drawings, charts, whiteboard drawings, diagrams, tables, etc.).

\subsection{The Practice}

The practice (execution of exercises) is used not only for developing skills and abilities, but also for improving knowledge and learning its practical application.

The Practice - is repeated execution of the action (motor or intellectual), organized in a certain way and always oriented (with each repetition) towards a particular outcome (improved quality of execution).

Under the influence of the conditions specific to development of motor or intellectual skills, the practice method has certain peculiarities when used in one or the other of these processes.

For developing motor skills and abilities, the practice is twofold:

- practice for learning the motor action and for developing the skill and the ability;

- training (practice to maintain and improve the skill).

When learning any motor action, there are some essential rules that should be followed.

- to explain the necessity for learning the motor action; learning should take place in conditions similar to those where the motor action will be used (applied conditions).

- it is absolutely necessary that the components of the movement (action) be always and rigorously practiced in the same order, that the structure of the 
movement (action) be always the same, during every practice, until it turns into a skill.

- whenever it is possible, the instructor should verbally emphasize (approve, evaluate) the correct execution of the movement (action), the obtained results should be specifically known.

- the initial learning of the motor action should take place at a slow pace.

During motor action learning, regardless of the process through which it is done (full or by parts) attention should be focused on correct execution (continuous decrease in the number of mistakes until their complete elimination).

As a result of repeated practice, as it was pointed out, the component movements of the motor action are made increasingly faster. The main condition that must met when executing the motor action, before moving to the automatization stage, is correcting the errors of execution (of the permanent mistakes that result from not knowing the right action). During the automatization stage, accepting the existence of execution mistakes is a serious pedagogical error because, by continuing practicing, the wrong execution will become an automatism, and, because of the durability of the temporary connections after developing the skill, subsequent correction will be difficult.

Regarding training, after building the motor skill we should not stop practicing it, but do it more rarely, at longer time intervals. The practice for maintaining and improving the motor skills is characterized by the fact that it can take place in various circumstances and in changed conditions.

In the educational process of the military organization, integrating the developed skills for completion of complex activities is common practice: the skills developed during field training, engineer training, NBC protection, signal training etc. are all integrated within artillery training, execution of tactical exercises, artillery shooting training.

\subsection{The Individual study}

Manuals, regulations, instructions, lectures and the other works suggested by biography represent, together with teaching activities and instructors' words, a source of knowledge. [3]

Generally, the methodology of the individual study has two main directions:

- to establish a right correlation between teaching and individual study;

- to acquire efficient methods and techniques of study and to turn them into skills and abilities (to study a text and divide it into chapters, to establish main and secondary ideas, to underline and take notes, to make a presentation agenda, to make a summary, to make a chart or a graphic design, to learn by memorizing logically and by synthesizing). [4]

The individual study is necessary because full acquisition of the information presented (learning the new information) does not always take place; what happens is understanding it; the new knowledge is acquired partially and the notes reflect only the essential part; the work for acquiring the new knowledge (learning) consists not only in studying the notes, but also the manuals, the regulations, the scientific works; the teaching sessions cannot include all information regarding a specific issue, only the most important aspects; in order to complete the research and acquire more knowledge about the taught issues, it is necessary to study individually, to study scientific works and specialized magazines. It should also be indicated what aspects, included in the regulations (manual), were not approached and should be acquired through individual study.

\section{Conclusions}

The effectiveness of training depends, largely, on methodical teaching, on the right, skilful use of the teaching methods applied in the educational process. Consequently, the value of a method can be seen only by applying it. A good method fully corresponds to the particular 
conditions of a certain part of the teaching session and ensures that its operational objectives are fulfilled and that the mental process corresponding to the objectives of the teaching session takes place in the best conditions. At the same time, the efficiency of the methods employed depends, at a large extent, on the art of the teaching staff involved in training activities.

\section{References}

[1] CERGHIT I., Metode de învăţământ, București, Editura Didactică şi Pedagogică, 1980.

[2] COSMOVICI, A., Psihologie generală, Iaşi, Editura Polirom, 1996.

[3] CRISTEA S., Pedagogie Generală. Managementul Educaţiei, Bucureşti, Editura Didactică şi Pedagogică, R.A. 1996.

[4] CUCOŞ C-tin, Istoria pedagogiei, Iaşi, Editura Polirom, 2001. 